\title{
Journals Evaluation and the Application Based on Entropy-TOPSIS
}

\author{
Wen-Tao Duan ${ }^{1}$, Yuan-Biao Zhang ${ }^{2,3} \& \mathrm{He} \mathrm{Nie}^{1}$ \\ ${ }^{1}$ Electrical and Information School, Jinan University, Zhuhai, China \\ ${ }^{2}$ Packaging Engineering Institute, Jinan University, Zhuhai, China \\ ${ }^{3}$ Key Laboratory of Product Packaging and Logistics of Guangdong Higher Education Institutes, Jinan University, \\ Zhuhai, China
}

Correspondence: Yuan-Biao Zhang, Packaging Engineering Institute, Jinan University, Zhuhai, 519070, China. E-mail: zybt@jnu.edu.cn

Received: December 2, 2014

Accepted: January 2, $2015 \quad$ Online Published: April 27, 2015

doi:10.5539/emr.v4n1p30

URL: http://dx.doi.org/10.5539/emr.v4n1p30

\begin{abstract}
This paper presented the objective evaluation method of Journals analyzed by the TOPSIS based on entropy weight and compared it with the traditional single valuation way. Based on the evaluation index, the objective weight of the index was calculated with the entropy method, the journals selected analyzed by TOPSIS. With the weights from normalized entropy, this paper calculated the distance from each journal to the best and the worst and worked out the rankings of the journal according to the proximity. Then the results from Principal Component Analysis and Single Evaluation Method were compared and analyzed, making the result of evaluating more objective and accurate.
\end{abstract}

Keywords: entropy coefficient, TOPSIS, comprehensive evaluation, journals, Principal Component Analysis (PCA)

\section{Introduction}

With the development of science, more and more different periodicals are published providing readers a wealth of information and resource. While providing numerous documents, a scientific evaluation system is needed to recommend and choose all the types of periodicals. In recent years studies on the evaluation method and system of the scientific and technological periodical appears constantly, comprehensive evaluation of index weight has become a hot spot, mainly including objective weighting methods, subjective weighting methods and combination giving-weight-value. Zhong et al. (1999) made use of the factor analysis approach to filter and establish the evaluation system; Zhou et al. (2006) evaluated the main Journals of Mathematics in China by the factor analysis approach; Guan et al. (2004) utilized the principal component analysis to do the comment ranking for the core foreign journals; Wang et al. (2003) conducted the application of WRSR methods incomprehensive evaluation of the medical journals.

TOPSIS et al. (2008) based on entropy Method is an evaluation system which can reflect the actual working condition objectively, it has a huge application value in the practice. The score is determined by calculating the entropy value, the weight of the index and the corresponding best and worst value. PCA et al. (2011) however doesn't use the Weighting coefficient, which improves the objectivity and quality of the comments. As one of the multivariate analysis methods in mathematical statistics, it can avoid the shortcoming of human subjectivity. In determining the index weight and make the result more objective.

This paper conducted the academic evaluation on the selected journals based on the TOPSIS and compared it with the traditional way, that is using the expanding the impact factors as the single evaluation index.

\section{The Academic Level of Journals Evaluation Model upon TOPSIS Based on Entropy Method}

Considering the influence different index have on the academic level, this paper made a comprehensive evaluation on the selected journals on the base of TOPSIS. Nine impact indexes on journals were selected and the objective weight of each index calculated by entropy method, with this, we eliminated the effects from subjective factors and made it more objective. Based on the data from the objective weight, the comprehensive evaluation was conducted with TOPSIS, finally stated and verified by PCA, thus we got the way to improve the evaluation of single index. 


\subsection{Evaluation Indicators of Journals}

According to the data from documents, there are a few index that may affect the academic level and they are as followed:

(1) Extended total cited version number;

(2) Extended influence factor;

(3) Extended immediacy index;

(4) Extended cited rate;

(5) Extended number of citing sci-tech journals;

(6) Extended disciplines impact indicators;

(7) Extended discipline diffusion index;

(8) Extend cited half-life;

(9) Extended $h$ index.

The traditional evaluation of single index mainly refers to make the evaluation according to the two universal evaluation indexes of extended influence and extended total cited version number. That is we can get the position of the journal in the same category by comparing and ordering extended influence and extended total cited version number, thus valuing and evaluating its academic influence and position. But with it as the only measure to evaluate journals, there are shortcomings - the influences from other factors are overlooked. Due to simplifying too much, the objectivity and reliability of the method are under suspicion, especially in these sci-tech journals with great influence but low level of extended influence factor et al. (2007).

\subsection{TOPSIS Based on Entropy Weight Method}

Entropy-weighting TOPSIS et al. (2011) is a common method in multi-objective decision nuking method with finite alternatives. It is based on the normalized original data matrix, an objective weight determination from the change of metric. Then we can get the optimal value and the worst, calculate the distance from certain scheme to the best and the worst and worked out the rankings of the journal according to the proximity.

Concrete steps of Entropy-weighting TOPSIS method are as follows:

(1) Establish the evaluated matrix with all positive number, supposing it has $n$ samples and each sample has pindicators. So the original matrix is as follow

$$
x=\left(x_{i j}\right)_{n \times p}(i=1,2, \cdots, n, j=1,2, \cdots, p)
$$

Then we standardize the evaluated data of the journals indicators. Concerning the trends and dimension of the indicators, we transform the negative indicators into the positive indicators so that all indicators can be compared homodromously. Here we use the Z-score method to standardize the data, as follow:

$$
X_{i j}^{\prime}=\frac{X^{i j}-\overline{X_{j}}}{S_{j}}
$$

$$
\begin{aligned}
& X_{i j}^{\prime} \text { are the standardized data,as follow: } \\
& \qquad X_{i j}=x_{i j} / \sum_{i=1}^{m} x_{i j}
\end{aligned}
$$

(2) Calculate the entropy of the indicator $\mathrm{j}$

$$
e_{j}=-\frac{1}{\ln m} \sum_{i=1}^{m} X_{i j} \ln X_{i j}(1 \leq j \leq n)
$$


(3) Calculate the weight of the 9 indicators

$$
\begin{gathered}
g_{j}=1-e_{j}(1 \leq j \leq n) \\
w_{j}=g_{i} / \sum_{i=1}^{n} g_{i}(1 \leq j \leq n)
\end{gathered}
$$

(4) Weighting the standardized data

We suppose that $X_{i j}^{F}$ is the $\mathrm{j}$-th value in ith indicator of weighting value of the standardized data. According to the weighting rule of the standardized data, we can get the results as follow:

$$
X_{i j}^{\prime}=X_{i j} w_{j}
$$

(5) Suppose the j-thattribute value of positive ideal solution $z^{+}$is $z^{-}$, and the j-thattribute value of negative ideal solution $z^{+}$is. $z^{-}$So, positive ideal solution is denoted by:

$$
z^{+}=\min _{i}\left\{z_{i j}\right\}, i=1,2, \ldots, m ; j=1,2, \ldots, n
$$

negative ideal solution is:

$$
z^{-}=\max _{i}\left\{z_{i j}\right\}, i=1,2, \ldots, m ; j=1,2, \ldots, n
$$

(6) Calculate the distance between the $\mathrm{j}$-the valuation object and ideal solution. $d^{+}$is the distancebetween thej-thevaluation objectand positive ideal solution $z^{+} \cdot d^{-}$is the distance between the $\mathrm{j}$ - the valuation object and negative ideal solution $z^{-}$:

$$
d_{i}^{+}=\sqrt{\sum_{j=1}^{4}\left(z_{i j}-z_{j}^{+}\right)^{2}}, i=1,2, \ldots, m
$$

$\mathrm{d}^{-}$is the distance between the $\mathrm{j}$-the valuation object and negative ideal solution $z^{-}$:

$$
d_{i}^{-}=\sqrt{\sum_{j=1}^{4}\left(z_{i j}-z_{j}^{-}\right)^{2}}, i=1,2, \ldots, m
$$

(7) Calculate relative comprehensive evaluation degree of each object and rank them.

Comprehensive evaluation value for each evaluation object is:

$$
C_{i}=\frac{d_{i}^{-}}{d_{i}^{+}+d_{i}^{-}}, i=1,2, \cdots \cdots m
$$

Closeness between the evaluation object and the ideal solution can be obtained. Then we rank them according to $C_{i}$. If the value is bigger, indicating that the corresponding evaluation object closer to the optimal level; conversely, the value is closer to 0 , the evaluation object represents the worst level.

\subsection{Principal Component Analysis}

This study determines the extensions according to the total contribution of the principle components, the weight from the variance of the principle components. It can eliminate the deviation from the relativity between the index and reduce the calculating dimension, which makes it easier to choose the index and improve the credit of the valuation. With this method, we can avoid indetermination and ensure to decide correctly and objectively.

To reduce the number of the selected index and dimension cutting down the calculation quantity, this paper determined the principle components when the cumulative percent of the variance is over $90 \%$ for they contained 
most information. Then we calculated the evaluation of the selected journals and the score with the cumulative percent of the variance as the weight of the component then finally reached the comprehensive value.

\section{Instance Analysis}

This paper uses data and evaluation index in references (He et al. 2013) and calculates for the for economic journals with matlab and SPSS19 et al. (2012). Then we utilize entropy-TOPSIS method to evaluate these journals.

\subsection{The Academic Level of Economic Journals Evaluation Model upon TOPSIS Based on Entropy Method}

We evaluate the 20 economic journals (Let B1, B2, B3, B4, B5, B6, B8, B9, respectively stand for: Extended total cited version number, extended influence factor, extended immediacy index, extended cited rate, extended number of citing sci-tech journals, extended disciplines impact indicators, extended discipline diffusion index, extend cited half-life, extended H Index）, as shown in table.

Table 1. Evaluation data of Economic journals

\begin{tabular}{llllllllll}
\hline Journal Name & B1 & B2 & B3 & B4 & B5 & B6 & B7 & B8 & B9 \\
\hline Sci-Tech and Industry & 724 & 0.348 & 0.067 & 0.98 & 384 & 0.25 & 3.37 & 3.40 & 5 \\
A\&E Research & 323 & 0.793 & 0.156 & 0.99 & 156 & 0.23 & 1.37 & 3.78 & 4 \\
South China. J of Economics & 1029 & 1.745 & 0.128 & 0.88 & 439 & 0.45 & 3.85 & 5.13 & 9 \\
Shangqing & 1070 & 0.046 & 0.011 & 0.99 & 329 & 0.15 & 2.89 & 2.06 & 4 \\
Commercial Research & 4644 & 0.866 & 0.135 & 0.99 & 1031 & 0.49 & 9.04 & 6.13 & 8 \\
Productivity Research & 3638 & 0.495 & 0.082 & 0.99 & 1001 & 0.53 & 8.78 & 3.98 & 7 \\
The J of World Economic & 3792 & 3.27 & 0.252 & 0.98 & 650 & 0.61 & 5.7 & 6.3 & 18 \\
World Economy Study & 1663 & 1.272 & 0.131 & 0.97 & 493 & 0.54 & 4.32 & 4.92 & 10 \\
Special Zone Economy & 2720 & 0.317 & 0.08 & 0.98 & 813 & 0.43 & 7.13 & 4.08 & 6 \\
Contemporary Eco of Japan & 409 & 1.198 & 0.161 & 0.88 & 210 & 0.25 & 1.84 & 4.17 & 5 \\
Asia-Pacific Econ Review & 714 & 0.774 & 0.21 & 0.94 & 326 & 0.35 & 2.86 & 3.64 & 5 \\
Zhejiang Economy & 442 & 0.122 & 0.013 & 1.00 & 255 & 0.27 & 2.24 & 4.62 & 4 \\
China D. Observation & 598 & 0.537 & 0.072 & 1.00 & 368 & 0.33 & 3.23 & 3.51 & 6 \\
Economic Issues in China & 369 & 0.922 & 0.153 & 0.93 & 209 & 0.32 & 1.83 & 4.53 & 5 \\
Resource\& Industry & 982 & 0.733 & 0.019 & 0.89 & 429 & 0.29 & 3.76 & 4.17 & 7 \\
QuanqiuK.JLiaowang & 251 & 0.236 & 0.057 & 0.9 & 141 & 0.09 & 1.24 & 5.41 & 3 \\
TianfuXinlun & 635 & 0.397 & 0.098 & 0.97 & 386 & 0.26 & 3.39 & 4.86 & 4 \\
Modern Economics (PM) & 720 & 0.188 & 0.028 & 0.99 & 321 & 0.25 & 2.82 & 3.56 & 4 \\
Modern Econ Information & 4497 & 0.291 & 0.046 & 0.96 & 677 & 0.33 & 5.94 & 2.33 & 9 \\
Nankai Economic Studies & 1138 & 1.518 & 0.444 & 1.00 & 450 & 0.52 & 3.95 & 6.79 & 9 \\
\hline
\end{tabular}

Due to the 9 indicators of this paper are all very large indicators, it need not be processed for common trends. SPSS will analyze the original data automatically. After standardizing the data in table1, generate the data as shown in table 2. 
Table 2. The standardized evaluation data of Economic journals

\begin{tabular}{llllllllll}
\hline Journal Name & B1 & B2 & B3 & B4 & B5 & B6 & B7 & B8 & B9 \\
\hline Sci-Tech and Industry & -0.54 & -0.61 & -0.50 & 0.47 & -0.27 & -0.69 & -0.27 & -0.80 & -0.47 \\
A\&E Research & -0.81 & -0.01 & 0.38 & 0.70 & -1.15 & -0.84 & -1.15 & -0.48 & -0.77 \\
South China. J of & -0.33 & 1.26 & 0.11 & -1.92 & -0.06 & 0.74 & -0.06 & 0.63 & 0.71 \\
Economics & & & & & & & & & \\
Shangqing & -0.31 & -1.01 & -1.05 & 0.70 & -0.48 & -1.41 & -0.48 & -1.90 & -0.77 \\
Commercial Research & 2.13 & 0.08 & 0.18 & 0.70 & 2.24 & 1.02 & 2.24 & 1.45 & 0.41 \\
Productivity Research & 1.44 & -0.41 & -0.35 & 0.70 & 2.12 & 1.31 & 2.12 & -0.32 & 0.12 \\
The J of World Economic & 1.55 & 3.29 & 1.33 & 0.47 & 0.76 & 1.88 & 0.76 & 1.59 & 3.36 \\
World Economy Study & 0.10 & 0.63 & 0.14 & 0.23 & 0.15 & 1.38 & 0.15 & 0.45 & 1.00 \\
Special Zone Economy & 0.82 & -0.65 & -0.37 & 0.47 & 1.39 & 0.59 & 1.39 & -0.24 & -0.18 \\
Contemporary Eco of Japan & -0.76 & 0.53 & 0.43 & -1.92 & -0.94 & -0.69 & -0.95 & -0.16 & -0.47 \\
Asia-Pacific Econ Review & -0.55 & -0.04 & 0.92 & -0.49 & -0.49 & 0.02 & -0.49 & -0.60 & -0.47 \\
Zhejiang Economy & -0.73 & -0.91 & -1.03 & 0.94 & -0.77 & -0.55 & -0.77 & 0.21 & -0.77 \\
China D. Observation & -0.63 & -0.36 & -0.45 & 0.94 & -0.33 & -0.12 & -0.33 & -0.71 & -0.18 \\
Economic Issues in China & -0.78 & 0.16 & 0.35 & -0.73 & -0.95 & -0.19 & -0.95 & 0.13 & -0.47 \\
Resource \& Industry & -0.37 & -0.09 & -0.97 & -1.68 & -0.09 & -0.41 & -0.10 & -0.16 & 0.12 \\
Quanqiu K. JLiaowang & -0.86 & -0.76 & -0.59 & -1.45 & -1.21 & -1.84 & -1.21 & 0.86 & -1.06 \\
TianfuXinlun & -0.60 & -0.54 & -0.19 & 0.23 & -0.26 & -0.62 & -0.26 & 0.40 & -0.77 \\
Modern Economics (PM) & -0.54 & -0.82 & -0.88 & 0.70 & -0.51 & -0.69 & -0.51 & -0.67 & -0.77 \\
Modern Econ Information & 2.03 & -0.68 & -0.70 & -0.01 & 0.87 & -0.12 & 0.87 & -1.68 & 0.71 \\
Nankai Economic Studies & -0.26 & 0.95 & 3.23 & 0.94 & -0.01 & 1.24 & -0.01 & 1.99 & 0.71 \\
\hline
\end{tabular}

We use the entropy-TOPSIS method to evaluate the journals in table1 by matlab. According to the entropy weight, we conduct the weights of the 9 indicators: $0.109,0.109,0.109,0.117,0.110,0.112,0.11,0.113,0.109$. Then figure out the comprehensive values and their ranks, as shown in table 3.

Table 3. Evaluation results of the Economic journals

\begin{tabular}{lll|lll}
\hline Journal Name & TOPSIS & rank & Journal Name & TOPSIS & rank \\
\hline Sci-Tech and Industry & 0.2047 & 18 & Asia-Pacific Econ Review & 0.3156 & 11 \\
A\&E Research & 0.2106 & 17 & Zhejiang Economy & 0.2114 & 16 \\
South China. J of Economics & 0.4837 & 4 & China D. Observation & 0.2364 & 15 \\
Shangqing & 0.1114 & 20 & Economic Issues in China & 0.3092 & 12 \\
Commercial Research & 0.5572 & 2 & Resource \& Industry & 0.3431 & 9 \\
Productivity Research & 0.479 & 5 & Quanqiu K.JLiaowang & 0.28 & 13 \\
The J of World Economic & 0.7033 & 1 & TianfuXinlun & 0.2712 & 14 \\
World Economy Study & 0.4564 & 6 & Modern Economics (PM) & 0.1757 & 19 \\
Special Zone Economy & 0.4081 & 7 & Modern Econ Information & 0.382 & 8 \\
Contemporary Eco of Japan & 0.342 & 10 & Nankai Economic Studies & 0.5446 & 3 \\
\hline
\end{tabular}




\subsection{The Academic Level of Economic Journals Evaluation Model Based on PCA}

After standardizing the data, we obtain correlation matrix of the data and its characteristic root and the accumulative contribution which choose $90 \%$ as advance accumulative contribution. According to the contribution of each principal component, the comprehensive evaluated modell is as follow:

$$
Z=0.51259 Z_{1}+0.25776 Z_{2}+0.10391 Z_{3}
$$

\subsection{Result and Analyze}

Compared entropy-TOPSIS method with PCA and conventional evaluated method, the ranking is as shown in table 4:

Table 4. Comprehensive ranking

\begin{tabular}{lllll}
\hline & Journal Name & Entropy-TOPSIS & PCA & Simple Method \\
\hline 1 & Sci-Tech and Industry & 18 & 17 & 16 \\
2 & A\&E Research & 17 & 10 & 13 \\
3 & South China. J of Economics & 4 & 5 & 5 \\
4 & Shangqing & 20 & 20 & 17 \\
5 & Commercial Research & 2 & 3 & 2 \\
6 & Productivity Research & 5 & 6 & 4 \\
7 & The J of World Economic & 1 & 1 & 1 \\
8 & World Economy Study & 6 & 4 & 6 \\
9 & Special Zone Economy & 7 & 7 & 8 \\
10 & Contemporary Eco of Japan & 10 & 11 & 9 \\
11 & Asia-Pacific Econ Review & 11 & 8 & 11 \\
12 & Zhejiang Economy & 16 & 16 & 20 \\
13 & China D. Observation & 15 & 13 & 14 \\
14 & Economic Issues in China & 12 & 9 & 12 \\
15 & Resource\& Industry & 9 & 15 & 10 \\
16 & Quanqiu K.J Liaowang & 13 & 19 & 19 \\
17 & TianfuXinlun & 14 & 12 & 15 \\
18 & Modern Economics (PM) & 19 & 18 & 18 \\
19 & Modern Econ Information & 8 & 14 & 3 \\
20 & Nankai Economic Studies & 3 & 2 & 7 \\
\hline
\end{tabular}

The top 5 journals by entropy-TOPSIS method are The Journal of World Economic, Commercial Research, Nankai Economic Studies and South China Journal of Economics Productivity Research while the top 5 journals by PCA are The Journal of World Economic, Nankai Economic Studies, Commercial Research, World Economy Study and South China Journal of Economics. The two results are not completely different but very close. For example, The Journal of World Economic, one of the best economic journals in China, ranks first in extended influence factor. In the first three evaluated results of journals, The Journal of World Economic ranks first in extended influence factor、extended disciplines impact indicators and extended disciplines impact indicators. Nankai Economic Studies ranks first in extended immediacy index and extended cited rate when Commercial Research ranks as the top of Extended total cited version number、 extended number of citing sci-tech journals and extended discipline diffusion index. They occupy the top of all the indicators, which are related a lot to their ranks. So it illustrates that the TOPSIS based on entropy can evaluate objectively the academic levels of these journals. Compared with the simple evaluated method, the new method improve a to some extent because it can take more factors into consideration such longer time and other objective factors. 


\section{Conclusion}

The paper uses TOPSIS based on entropy weight to evaluate the 9 indicators of the 20 economic journals. We exclude subjective factors with method of determining the objective weight and calculate the TOPSIS value after weighting the data. At first standardizing the journals' data and calculating the weights of all the indicators according to entropy. After weighing the data, we can calculate and obtain the score of TOPSIS. Relative proximity is between 0 and 1 . If the value is closer to 1 , indicating that the corresponding evaluation object closer to the optimal level. Whereas it is closer to the worst level. At the same time, PCA can prove its reasonability that it can impact on readers and citers to some extent.

The analysis procedure of TOPSIS based on is simple, it can reflect the evaluation date of each index directly, starting from the objective weight and based on the objective data, eliminating the interruption from the subjective factors. It can also adequately mine the intrinsic link of data and show the objectivity of the model. Other objective methods can obtain the evaluated results such as PCA and RSR but their processes are more complex. If we got the index weight totally from experts' advice, then it lacks science and objectivity. However, extended influence factor only includes the cites in 2 years. It is partial to evaluate the journals according to extended influence factor so comprehensive method is more persuasive.

The evaluation system is not a single evaluation system, we also need to consider the conditions when applying and the accuracy. Although TOPSIS based on the entropy can avoid subjective factors, this weight result may not stand for the real situation. A better way to do this is to combine the objective weight method and the advice from experts to do an oriented research, with this we can optimize the model in evaluating the academic level of journals, a further study need to conduct to apply the subjective factors.

\section{Acknowledgements}

The project of the college students' innovation and entrepreneurship training plan is in Jinan university (national level) (No. 201410559004).

\section{References}

Guan, J., Chen, W. K., \& Li, Z. F. (2004). Comprehensive Evaluation of Foreign Core Journals-the Application of PCA. Journal of medical intelligence, 1, 13-16. Retrieved form http://10.3969/j.issn.1673-6036.2004.01.005

He, D. F. et al. (2013). China's science and technology journal citation reports (KuoKan version). BeiJing: Science and technology literature press.

Li, G. C., Guo, T. Ch, \& Yan, Q. (2011). Evaluation Model and Empirical Study of Human All-Round Development Based on Entropy Weight and TOPSIS. Journal of Systems Engineering, 26(3), 401-407.

Li, J. H., Wang, Zh. K., Sun, M. J., \& Su, H. Y. (2007). Rerecognization of the Impact Factor of the Scitech Periodicals of China. Chin J Med LibrInfSci, 16(1), 6-9.

Shi, L. W. (2012). SPSS19.0 Statistical Analysis from Entry to the Master (Vol 1). Tsinghua University Press.

Wang, J. N. (2011). Improved TOPSIS Model Base on Entropy Weight Research. Public Communication of Science \&Technology, 2, 11-12.

Wang, J., \& Xu, T. H. (2013). The RSR in the Application of the Medical Academic Journals of Sci-tech Quality. Comprehensive Evaluation Journal of Mathatical Medicine, 16(3), 266-267. Retrieved form http://10.3969/j.issn.1004-4337.2003.03.041

Zhai, Z. H. (1999). Research on Evaluation of Scientific Research Standard of Scientific and Technical Personnel. Systems Engineering-Theory \& Practice, 11, 51-54. Retrieved form http://10.3321/j.issn:1000-6788.1999.11.009

Zhang, H., Zhao, H. X., Liu, Y. P., \& Tao, W. W. (2008). The Evaluation Method of Sci-tech Journals Base on PCA. ActaEditologica, 20(1), 87-90.

Zhou, L., \& Zhang, L. L. (2006). The Evaluating to Some Major Mathematics Journals in China by Factor Analysis Method. Journal Of Huaibei Cool Industry Teachers College, 127(2). Retrieved form http://10.3969/j.issn.2095-0691.2006.02.015 


\section{Copyrights}

Copyright for this articleis retained by the author(s), with first publication rights granted to the journal.

This is an open-access article distributed under the terms and conditions of the Creative Commons Attribution license (http://creativecommons.org/licenses/by/3.0/). 